\title{
EDITORIAL
}

\section{The airway smooth muscle cell: a major contributor to asthma?}

\author{
K.F. Chung*, P.J. Sterk**
}

Since REISSEISEN [1] first described the airway smooth muscle (ASM) of the bronchial tree extending from the central airways to the level of the membranous bronchiole in 1822, ignorance of the physiological function of this prominent component of the airways in health and disease has continued. The above question will surely be answered one day, when a model of conducting airways devoid of ASM is developed. Paradoxically, it seems clear that under disease states, such as asthma, ASM contributes to a large extent to airway luminal narrowing and, therefore, to the development of airways obstruction. Therefore, it does not come as a surprise that much work has been targeted towards elucidating the physiology, biochemistry and pharmacology of the contractile events of ASM.

Biologists have also been concerned with whether there are any fundamental abnormalities of ASM in asthma [2] that could account for the very characteristic feature of bronchial hyperresponsiveness, commonly observed in asthma and sometimes in chronic obstructive pulmonary disease. Such bronchial hyperresponsiveness includes an increase in sensitivity as well as in maximal response to bronchoconstrictor stimuli in vivo [3]. The failure to observe any relationship between these features of hyperresponsiveness in vivo and ASM contractility in vitro during the late 1980s [4] seriously weakened the case for a role for ASM in disease. However, these experiments were almost exclusively performed in nonasthmatics in whom lung resection material could be obtained because of malignancies. In the few instances in which tissue from patients with fatal asthma was available, it appeared that ASM did show abnormalities in vitro, such as increased maximal contractility and impaired relaxant responses [5].

There are various possibilities for the involvement of ASM in diseases such as asthma: excessive smooth muscle shortening secondary to decreased airway elastance or altered airway/parenchymal interdependence, an excessive amount of ASM causing more force generation, or an excessive velocity of contraction [6]. In a previous review in this Journal, FREDBERG [7] emphasized the importance of the delicate equilibrium of the dynamics of smooth muscle behaviour itself (cross-bridge cycling rate and cellular

\footnotetext{
*National Heart \& Lung Institute, Imperial College School of Medicine, London, UK. **Dept of Pulmonology, Leiden University Medical Center, Leiden, the Netherlands.

Correspondence: K.F. Chung, National Heart \& Lung Institute, Imperial College School of Medicine and Royal Brompton Hospital, London SW3 6LY, UK. Fax: 442073518126.
}

plasticity) and of its mechanical coupling to its direct environment. Certainly, finding out about the fundamental abnormality of ASM that accounts for the bronchial hyperresponsiveness in disease forms part of the Holy Grail of asthma. A clear objective, but one that is now to be solved!

The description of increased ASM bulk in the autopsy specimens of patients who have died because of status asthmaticus has been another milestone in the development of new ideas about the role and contribution of ASM in disease [8]. Certainly, this led to more recent studies on the proliferative behaviour of ASM, providing considerable information concerning the mediators of ASM proliferation and the subcellular mechanisms thereof, at least in vitro [9]. But, how does ASM proliferate in vivo?

Finally, although we have been accustomed to the idea that the ASM cell is mainly subject to the effects of mediators released from other neighbouring structural or inflammatory cells, more recent work indicates the pleotropic nature of these cells in producing a wide range of pro-inflammatory cytokines [10]. Therefore, this is a contractile tissue that can proliferate and be induced to release cytokines/mediators. Do these contractile, secretory and proliferative "phenotypes" coexist in the same muscle cell at the same time under certain conditions or do these cells alternate, influenced by the inflammatory milieu? Also, how do these phenotypes impinge on each other, particularly with regard to the contractile response? Thus, the most recent observations have created attractive hypotheses on the involvement of ASM in asthma.

In view of the explosion of new information on the physiology, biochemistry, pathology and pharmacology of ASM, in the year 2000, this Journal will be running a short series of reviews on the evolving ideas and novel findings. This series arose from a symposium on "The airway smooth muscle" at the 1998 ERS Congress in Geneva, Switzerland. The series will start with a contribution by GUNST and TANG [11] from Indianapolis, IN, USA, addressing the contractile apparatus and mechanical properties of ASM. Then, JAMES and CARROLL [12], from Perth, Australia, will focus on the structural changes of ASM in disease. CHUNG [13], from London, UK, will focus on the secretory aspects of ASM in relation to airways inflammation. HiRst et al. [14] will review the phenotypic diversity and proliferative changes in ASM. Subsequently, MARTIN et al. [15], from Montreal, Canada, will discuss the contribution of ASM to airway narrowing and bronchial hyperresponsiveness. HALL [16], from Nottingham, UK, will guide the reader through the second messengers, ion channels and basic pharmacology of ASM. 
Airway smooth muscle has awoken; its benign appearance hides a potentially multifaceted role in asthma. Paradoxically, how it functions in disease may eventually provide us with insights into its physiological role!

\section{References}

1. Reisseisen FD. Uber den Bau der Lungen. Berlin, 1822.

2. Stephens NL. Airway smooth muscle. Am Rev Respir Dis 1987; 135: 960-975.

3. Macklem PT. The clinical relevance of respiratory muscle research. Am Rev Respir Dis 1986; 134: 812-815.

4. De Jongste JC, Sterk PJ, Willems LNA, Mons H, Timmers MC, Kerrebijn KF. Comparison of maximal bronchoconstriction in vivo and airway smooth muscle responses in vitro in nonasthmatic humans. Am Rev Respir Dis 1988; 138: 321-326.

5. Bai TR. Abnormalities in airway smooth muscle in fatal asthma. Am Rev Respir Dis 1990; 141: 552-557.

6. Solway J, Fredberg JJ. Perhaps smooth muscle dysfunction contributes to asthmatic bronchial hyperresponsiveness after all. Am J Respir Cell Mol Biol 1997; 17: 144-146.

7. Fredberg JJ. Airway smooth muscle: flirting with disaster Eur Respir J 1998; 12: 1252-1256.

8. Ebina M, Takahashi T, Chiba T, Motomiya M. Cellular hypertrophy and hyperplasia of airway smooth muscle underlying bronchial asthma. A 3D morphometric study. Am Rev Respir Dis 1993; 148: 720-726.

9. Panettieri RA. Cellular and molecular mechanisms regulating airway smooth muscle proliferation and cell adhesion molecule expression. Am J Respir Crit Care Med 1998; 158: S133-S140.

10. Chung KF, Barnes PJ. Cytokines in asthma. Thorax 1999; 54: 825-857.

11. Gunst SJ, Tang DD. The contractile apparatus and mechanical properties of airway smooth muscle. Eur Respir $J$ 2000; 15: 600-616.

12. James A, Carroll N. Airway smooth muscle in health and disease; methods of measurement and relation to function. Eur Respir $J 2000$ (in press).

13. Chung KF. Airway smooth muscle cells: contributing to and regulating airway mucosal inflammation? Eur Respir $J 2000$ (in press).

14. Hirst SG, Walker TR, Chilvers ER. Phenotypic diversity and proliferative changes of airway smooth muscle in asthma. Eur Respir $J 2000$ (in press).

15. Martin JG, Duguet A, Eidelman DH. The contribution of airway smooth muscle to airway narrowing and bronchial hyperresponsiveness in disease. Eur Respir J 2000 (in press).

16. Hall IP. Second messengers, ion channels and pharmacology of airway smooth muscle. Eur Respir J 2000 (in press). 